\title{
THEORETICAL PREDICTION OF DYNAMIC AXIAL CRUSHING ON A SQUARE TUBE WITH EIGHT HOLES USED AS A CRUSH INITIATOR
}

\author{
Mohammad Malawat ${ }^{1 *}$, Danardono Agus Sumarsono ${ }^{1}$, Jos Istiyanto ${ }^{1}$, Gatot Prayogo ${ }^{1}$, \\ Felix Dionisius ${ }^{2}$ \\ ${ }^{1}$ Department of Mechanical Engineering, Faculty of Engineering, Universitas Indonesia, Kampus UI \\ Depok, Depok 16424, Indonesia \\ ${ }^{2}$ Department of Mechanical Engineering, Politeknik Negeri Indramayu, Jl. Raya Lohbener Lama \\ No.08, Indramayu 45252, Indonesia
}

(Received: August 2018 / Revised: January 2019 / Accepted: May 2019)

\begin{abstract}
Thin-walled square steel tubes are part of automobile structures, used as impact energy absorbers on crush boxes. Under axial crushing, such tubes sometimes produces unpredictable folding forms. There are three modes of dynamic axial crushing folding forms: the symmetric collapse mode; the asymmetric mixed collapse mode A; and the asymmetric mixed collapse mode B. The objective of this paper is to develop a theoretical prediction for the three modes on a thin-walled square steel tube with eight holes used as crush initiator. The basic folding mechanism is used to predict the dynamic axial crushing analysis on the tube. These theoretical analyses can also can be implemented in different crush initiator positions.

Two types of cross section $(\mathrm{c} / \mathrm{h})$ were used in this study: specimen $\mathrm{A}(\mathrm{c} / \mathrm{h}=60.42)$ and specimen B $(\mathrm{c} / \mathrm{h}=45.69)$. Thirty-six experimental drop test studies were conducted on the thin wall square tube. In addition, the results of a previous drop test were compared to the results of the theoretical prediction. The results show that the theoretical analysis has good agreement with the experimental drop test study. This study proposes nine formulas to predict average force, peak force and energy absorption of the dynamic axial crushing on the thin-walled square steel tube with eight holes of crush initiator. The limitation of these formulas, however, is that they are unable to show the relationship between force and time in a graph.
\end{abstract}

Keywords: Crush initiators; Dynamic axial crushing; Square tube

\section{INTRODUCTION}

Thin-walled tubes have been widely used in the automotive industry as energy absorber components because of their excellent energy properties and light weight. Over the years, many researchers have studied thin-walled tube structures through experiments, numerical simulations and theoretical analysis, and have attained in-depth understanding of the characteristics of energy absorption (Hu et al., 2019).

The crashworthiness of thin-walled structures with different cross-sectional configurations, including square (Sun et al., 2017); circular (Zhang et al., 2018); rectangular (Shena et al., 2017); star-shaped (Deng et al., 2018); elliptical (Ge et al., 2018; Xiong et al., 2018); tapered tubes (Tran, 2017); honeycomb (Palomba et al., 2018; Hu et al., 2019); multi-cell (Xie et al.,

\footnotetext{
*Corresponding author's email: m.malawat72@gmail.com, Tel. +62-81-310247730

Permalink/DOI: https://doi.org/10.14716/ijtech.v10i5.2297
} 
2017; Ding et al., 2018); and hybrid square tubes (Zhang et al., 2019), have been researched in detail. From these studies, it was well known that the most severe plastic deformation occurs near sectional corners of tubes, which could dissipate a great amount of energy due to membrane and bending deformation along the bending hinge lines ( $\mathrm{Hu}$ et al., 2019). For example, Shena et al. (2017) investigated the crashworthiness of rectangular single-, doubleand unequal triple-cell tubes made of aluminium alloy. An analytical formula for predicting the mean crushing force (MCF) of unequal triple-cell tubes was first derived. Quasi-static crushing experiments and finite element analysis (FEA) were then conducted in the axial direction for the three different tubes. The results from numerical simulations were compared in detail with data from experimental tests and theoretical predictions. It was found that the triple-cell tube exhibited the best crash performance, followed by its double- and single-cell counterparts. A multi-objective optimization design was employed to investigate the effect of the thickness of each plate and the arrangements of internal ribs on specific energy absorption (SEA) and MCF. An experimental study on the crashworthiness of star-shaped tubes under axial compression was conducted by Deng et al. (2018). A star-shaped tube with twelve corners produced global buckling in quasi-static compression, while such a tube with eight corners had a better energy absorption capacity than tubes with six and twelve corners. The deformation modes of quasistatic and dynamic impact were very similar. According to Ge et al. (2018), the elliptical crosssection becomes narrower compared to the circle one, which is also helpful in increasing the energy absorption of the thin-walled tube.

To enhance the energy absorption capability and reduce the initial peak crushing force of thinwalled tubes, the attention of many researchers has also been drawn to corrugated tubes (Mahbod \& Asgari, 2018), functionally graded thickness (FGT) tubes (Sun et al., 2017), foamfilled tubes (Xiong et al., 2018; Googarchin et al., 2019) and metal/composite hybrid tubes (Zhang et al., 2019). For instance, Mahbod and Asgari (2018) conducted a theoretical study to investigate the behavior of corrugated composite tubes under axial and oblique crushing. The corrugated model Cr6n16 improved CFE by about 343\% in comparison to the straight tube, without an sharp reduction in the SEA in axial crushing. The corrugated tube Cr6n18 increased the SEA by about $18 \%$, with the same value of CFE as the straight tube in oblique crushing. Sun et al. (2017) proposed uniform thickness (UT), axial functionally graded thickness (AFGT) and lateral functionally graded thickness (LFGT) for thin-walled square structures, and then investigated their crushing characteristics through theoretical, numerical and experimental approaches under axial crushing loads. These primary outcomes demonstrate that FGT structures have considerable potential as energy absorption devices for axial impact. In terms of the methods for improving energy absorption capacity, a theoretical and numerical investigation of the energy absorption behavior of foam-filled tapered multi-cell tubes was made by Googarchin et al. (2019). Their analysis indicates that the SEA in the crushing of the foamfilled tubes with three cell rows in the cross section and a taper angle equal to 7 degrees would be five times greater than that in the crushing of the reference tube.

In particular, for the energy absorption structures of bio-inspired design strategies, natural structural hierarchies were fruitful learning resources. Based on their results from experimental testing and numerical modelling, Zhang et al. (2018) concluded that a 2nd-order hierarchical circular tube (HCT) offers significantly greater energy absorption than non-hierarchical structures (0th order HCT). Sub-circle diameters and wall thickness have a significant effect on the crashworthiness indictors of 2nd order HCT. A bio-inspired bionic honeycomb tubular nested structure (BHTNS) was proposed and the energy absorption characteristics of this structure under axial crushing conditions were also investigated by systematic experiments, numerical simulations, and theoretical analysis (Hu et al., 2019). Finally, a theoretical model 
was developed to predict the Pmean of BHTNS. It was observed that the Pmean of the theoretical model was in good agreement with that from the numerical simulation.

There are some limitations in conducting experimental drop test studies. They need a high tower, rig, load cell, high-speed camera, LabVIEW software, and computer. Meanwhile, numerical analysis requires software such as ANSYS LS DYNA, LS DYNA, ABAQUS or Pam Crash. Significant costs are involved in setting up the two methods, which is the main reason why development of theoretical analysis is needed.

As mentioned above, this study is related to the theoretical predictions of Zhang et al. (2019), Tran et al. (2017), Ding et al. (2018), Sun et al. (2017) and Xie et al. (2017). However, the most common theoretical predictions for rectangular tubes are suggested by Abramowicz and Jones (1984) and Nguyen et al. (2013). In terms of the number of crush initiators, Nguyen et al. used one or two, while Abramowicz and Jones did not use any. From the point of view of the basic folding mechanism, Nguyen et al. employed the symmetric collapse mode, whereas Abramowicz and Jones used the asymmetric mixed collapse modes A and B, together with the symmetric collapse mode. Abramowicz and Jones suggested the prediction of an average force equation, while Nguyen et al. proposed prediction of average force and peak force equations. Nguyen et al. also used a coefficient of geometry to peak force equation. This study proposes a new concept for predicting dynamic axial crushing performance, including the use of an eight crush initiator, asymmetric mixed collapse modes A and B and symmetric collapse mode for the basic folding mechanism, and equations of average force, peak force and energy absorption. These prediction equations consider the coefficients of peak force and stress concentration. Finally, the objective of this study is to develop a theoretical prediction of dynamic axial crushing on a thin-walled square steel tube with eight holes used as a crush initiator.

\section{METHODS}

The basic folding mechanism method initially presented by Abramowicz and Jones (1984). was employed There are three different mechanisms of energy absorption which need to be considered in a thin-walled square tube structure (see Figure 1). The first is extensional deformation on a toroidal surface (E1), the second is bending around the horizontal hinge lines $\mathrm{AB}$ and $\mathrm{BC}(\mathrm{E} 2)$, and the third is bending around the inclined hinge lines $\mathrm{NB}$ and $\mathrm{BH}(\mathrm{E} 3)$.

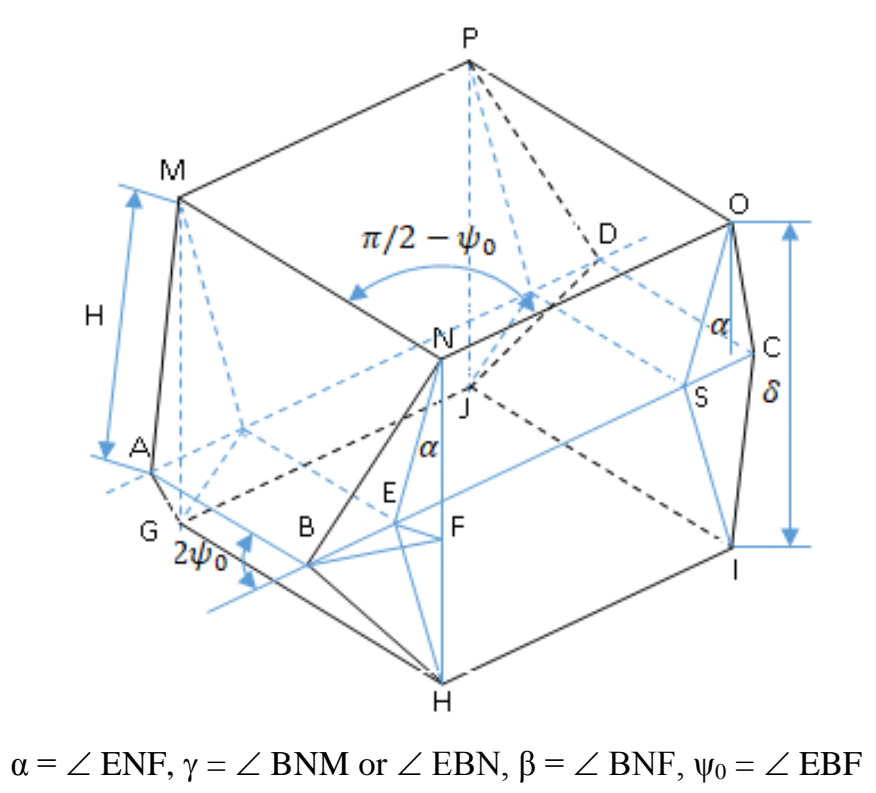

Figure 1 Basic folding mechanism of the thin-walled square tube 
Dynamic axial crushing causes $\alpha$ to start from $0^{\circ}$ to $\pi / 2$, while $\gamma$ begins from $\pi / 2$ to $0^{\circ}$. This happens simultaneously and continuously. The changes in $\alpha$ and $\gamma$ affect $\beta$ and $\psi_{0}$ according to the following equations (Najafi \& Rais-Rohani, 2011; Nguyen et al., 2013).

$$
\begin{aligned}
& \gamma=\tan ^{-1} \frac{\tan \psi_{0}}{\sin \alpha} \\
& \beta=\tan ^{-1} \frac{\tan \alpha}{\sin \psi_{0}}
\end{aligned}
$$

The three energy absorptions were predicted based on Equations 3, 4 and 5 to capture the asymmetric elements (type-I basic folding machanism) (Najafi \& Rais-Rohani, 2011).

$$
\begin{aligned}
& \mathrm{E}_{1}=\frac{16 \mathrm{M}_{0} \mathrm{HbI}_{1}}{\mathrm{~h}} \\
& \mathrm{E}_{2}=2 \mathrm{M}_{0} \pi \mathrm{c} \\
& \mathrm{E}_{3}=4 \mathrm{M}_{0} \mathrm{I}_{3} \frac{\mathrm{H}^{2}}{\mathrm{~b}}
\end{aligned}
$$

The equation of energy absorption for the symmetrical element (type-II basic folding machanism), including the conical surface, was predicted as follows (Najafi \& Rais-Rohani, 2011; Nguyen et al., 2013):

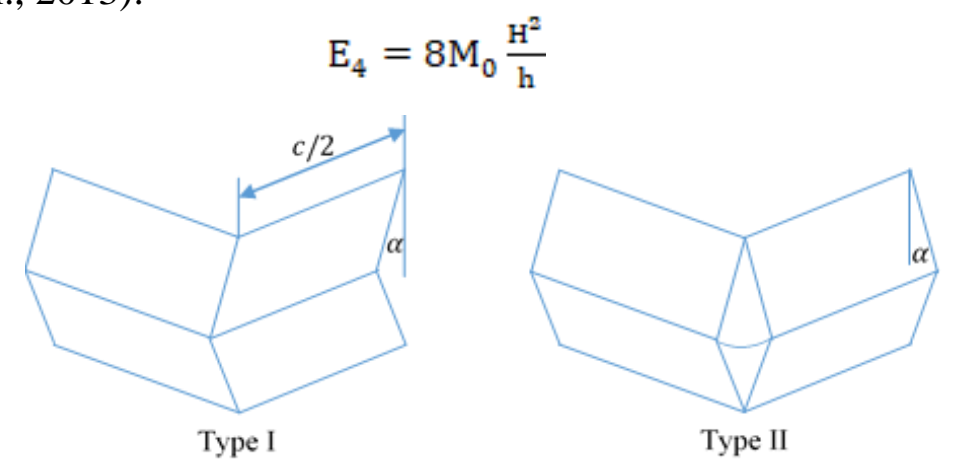

Figure 2 Type of folding in the corner of thin-walled square tube

When axial crushing force hits the thin-walled square column structure, the absorption folding energy achieves the plastic range of material properties. There are two kinds of folding, type-I and type-II, as shown in Figure 2. The absorption energy of type-1 and type-II in each corner of the square tube can be calculated by Equations 7 and 8, respectively:

$$
\begin{gathered}
\mathrm{E}_{\mathrm{I}}=\mathrm{M}_{0}\left(16 \mathrm{HI}_{1} \frac{\mathrm{b}}{\mathrm{h}}+2 \pi c+4 \mathrm{I}_{3} \frac{\mathrm{H}^{\mathrm{a}}}{\mathrm{b}}\right) \\
\mathrm{E}_{\mathrm{II}}=\mathrm{M}_{0}\left(\frac{8 \mathrm{H}^{2}}{\mathrm{~h}}+2 \pi \mathrm{c}+4 \mathrm{H}\right)
\end{gathered}
$$

where $\mathrm{M}_{0}=\sigma_{0} \mathrm{H}^{2} / 4, \sigma_{0}$ is the flow stress, $\mathrm{I}_{1}=0.555$ and $\mathrm{I}_{3}=1.148$. In addition, $\mathrm{H}$ is shown in Figure 1; $c$ is defined in Figure 2; $h$ is thickness; and $b$ is the radius of the toroidal region in the kinematically admissible velocity field. 


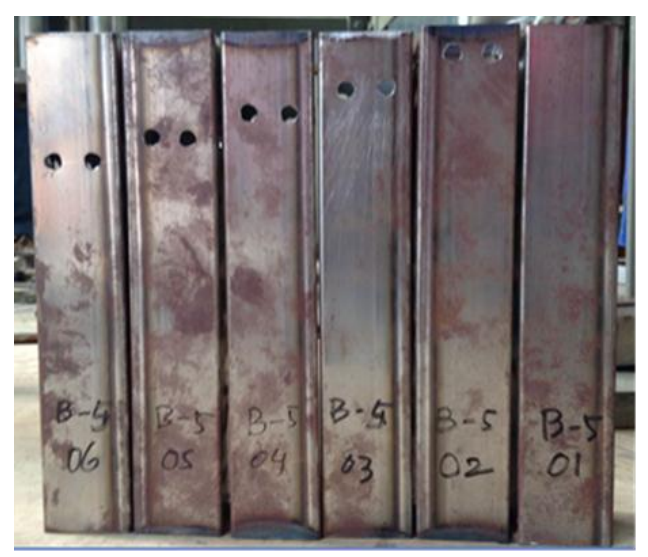

Figure 3 Geometry and the location of the eight holes on the square tube

The geometry and the location of the eight holes on square tube I (Sumarsono et al., 2015) are shown in Figure 3. The distance of the crush initiator from the upper side varied between 10 $\mathrm{mm}, 20 \mathrm{~mm}, 30 \mathrm{~mm}, 40 \mathrm{~mm}$ and $50 \mathrm{~mm}$. The thin-walled square column, as shown in Figure 3, has sixteen horizontal hinge lines. These lines are divided into two groups; the first has eight horizontal hinge lines where the hinge lines are not moving, while the second group has moved eight horizontal hinge lines. The length of the horizontal hinge line for the eight holes as a crush initiator is determined as $\mathrm{C}_{\text {equivalent: }}$

$$
c_{\text {equivalent }}=\left(1-\frac{\pi R^{2}}{c H i}\right) c
$$

The energy absorption through the horizontal hinge lines is determined as:

$$
\dot{E}_{2}=8 M_{0}\left(c+c_{\text {eqivalent }}\right) \dot{\alpha}
$$

by substituting Equation 9 into Equation 10, yield:

$$
\dot{E}_{2}=8 M_{0}\left(2-\frac{\pi R^{2}}{c H i}\right) c \dot{\alpha}
$$

By integrating Equation 11, the energy absorption for the horizontal hinge line at the crush initiator can then be written as:

$$
E_{2 i}=4 \pi M_{0}\left(2-\frac{\pi R^{2}}{c H i}\right) c
$$
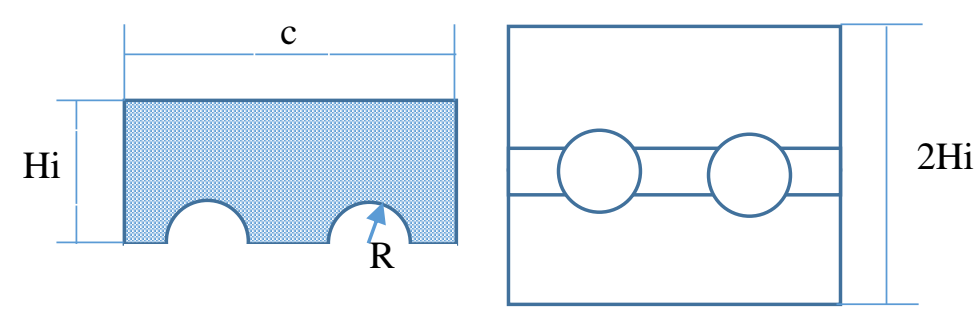

Figure 4 Geometry of the thin-walled square column with two holes in a line on each side

\section{RESULTS AND DISCUSSION}

\subsection{Symmetric Collapse Mode with Eight Holes}

\subsubsection{Mean force (Pm)}

According to Abramowicz and Jones (1984), the symmetric collapse mode consists of one layer, which comprises four type-I basic folding elements as internal energy, while external energy is defined as the total initial height $2 \mathrm{H}$ and mean force. The energy balance between internal and external energy can be written as: 


$$
P_{m} 2 \mathrm{H}=4 M_{0}\left(16 H I_{1} \frac{b}{h}+2 \pi c+4 I_{3} \frac{H^{2}}{b}\right)
$$

The eight hole crush initiator element in Equation 12 is substituted into Equation 13, yield:

with

$$
\frac{P_{m}}{M_{0}}=32 I_{1} \frac{b}{h}+\frac{2 \pi c}{H}\left(2-\frac{\pi R^{2}}{c H i}\right)+8 I_{3} \frac{H}{b}
$$

and

$$
\frac{H}{h}=0.99\left(\frac{c}{h}\right)^{\frac{2}{a}}
$$

$$
\frac{b}{h}=0.72\left(\frac{c}{h}\right)^{\frac{1}{a}}
$$

By subtituting Equations 15 and 16 into Equation 14, then:

$$
\frac{p_{m}}{M_{0}}=25.42\left(\frac{c}{h}\right)^{\frac{1}{a}}+6.34\left(2-\frac{\pi R^{2}}{c H i}\right)\left(\frac{c}{h}\right)^{\frac{1}{a}}
$$

\subsubsection{Effective crushing distance $\left(\delta_{1}\right)$}

The equation of effective crushing distance for a square column with symmetric collapse mode can be written as follows:

\subsubsection{Mean static force $\left(\bar{P}_{m}\right)$}

$$
\frac{\delta_{11}}{2 H}=0.73
$$

By dividing Equation 17 by Equation 18, the followed dimensionless equation can be used to predict the mean crushing load in a quasi-static test:

$$
\frac{p_{m}}{M_{0}}=34.82\left(\frac{c}{h}\right)^{\frac{1}{a}}+8.69\left(2-\frac{\pi R^{2}}{c H i}\right)\left(\frac{c}{h}\right)^{\frac{1}{a}}
$$

\subsubsection{Material strain rate sensivity $(\dot{\varepsilon})$}

Under dynamic loading, the material strain rate needs to be considered to predict the dynamic average crushing load. This rate for the symmetric collapse mode can be written as follows:

$$
\dot{\varepsilon}=0.33 \frac{V}{6}
$$

A detailed explanation can be found in reference.

\subsubsection{Cowper Symonds}

The Cowper-Symonds formula is an empirical uniaxial constitutive equation to show the relationship between static and dynamic loads and is written as follows:

$$
\frac{\sigma_{0}^{d}}{\sigma_{0}}=1+\left(\frac{\dot{\varepsilon}}{D}\right)^{\frac{\mu}{p}}
$$

By substituting Equation 20 into Equation 21 yield the following equation.

$$
\frac{\sigma_{0}^{d}}{\sigma_{0}}=1+\left(0.33 \frac{V}{e D}\right)^{\frac{1}{p}}
$$

where $v$ is the velocity, customary coefficient $D=40.4 s^{-1}$ and $p=5$ for mild steel from an experimental test conducted by Abramowicz and Jones (1984).

3.1.6. Mean dynamic force $\left(\bar{P}_{m}{ }^{d}\right)$

Multiplying Equations 19 and 22 gives the mean dynamic crushing loads as follows:

$$
\frac{p_{m}^{d}}{M_{0}}=\left\{1+\left(0.33 \frac{V}{c D}\right)^{\frac{1}{p}}\right\}\left\{34.82\left(\frac{c}{h}\right)^{\frac{1}{a}}+8.69\left(2-\frac{\pi R^{2}}{c H i}\right)\left(\frac{c}{h}\right)^{\frac{1}{a}}\right\}
$$




\subsubsection{Peak dynamic force $\left(\bar{P}_{\text {peak }}{ }^{d}\right)$}

Some authors have agreed that coefficient of geometry $\left(k_{G}\right)$ and the coefficient of stress concentration $\left(k_{T}\right)$ influence the peak dynamic force. On the other hand, the cofficient of experimental peak crushing force, $k_{o}=2.91$, affects the peak dynamic force (Nguyen et al., 2013). Moreover, other authors have found that the coefficient of stress concentration and coefficient of experimental peak crushing force show a close relation to the experimental result (Sumarsono et al., 2015; Malawat et al., 2017). Therefore, the peak dynamic force can be written as:

$$
\frac{p_{\text {peak }}{ }^{d}}{M_{0}}=k_{0}\left(\frac{K_{T}}{3}\right)\left\{1+\left(0.33 \frac{V}{c D}\right)^{\frac{1}{p}}\right\}\left\{34.82\left(\frac{c}{h}\right)^{\frac{1}{a}}+8.69\left(2-\frac{\pi R^{3}}{c H i}\right)\left(\frac{c}{h}\right)^{\frac{1}{a}}\right\}
$$

\subsubsection{Energy absorption $\left(E_{t}\right)$}

Prediction of energy absorption uses the mean dynamic force and displacement of folding:

$$
E_{t}=\delta_{1} M_{0}\left\{1+\left(0.33 \frac{V}{c D}\right)^{\frac{1}{p}}\right\}\left\{34.82\left(\frac{c}{h}\right)^{\frac{1}{3}}+8.69\left(2-\frac{\pi R^{2}}{c H i}\right)\left(\frac{c}{h}\right)^{\frac{1}{3}}\right\}
$$

\subsection{Asymmetric Mixed Collapse Mode A with Eight Holes}

\subsubsection{Mean force $\left(P_{m}\right)$}

According to Abramowicz and Jones (1984), the asymmetric collapse mode consists of two layers, which in turn consist of six type-I and two type-II basic folding elements as internal energy. The external energy is determined as the total initial height $4 \mathrm{H}$ and mean force. Furthermore, the energy balance between internal and external energy can be written as:

$$
P_{m} 4 H=M_{0}\left(96 H I_{1} \frac{b}{h}+16 \pi c+24 I_{3} \frac{H^{2}}{b}+\frac{16 H^{2}}{h}+8 H\right)
$$

By substituting the eight hole crush initiator element from Equation 12 into Equation 26, yield:

$$
\frac{P_{m}}{M_{0}}=24 I_{1} \frac{b}{h}+\frac{\pi c}{H}\left(2-\frac{\pi R^{2}}{c H i}\right)+\frac{2 \pi c}{H}+6 I_{3} \frac{H}{b}+\frac{4 H}{h}+2
$$

with

and

$$
\frac{H}{h}=0.73\left(\frac{c}{h}\right)^{\frac{2}{3}}
$$

$$
\frac{b}{h}=0.61\left(\frac{c}{h}\right)^{\frac{1}{a}}
$$

By subtituting Equations 28 and 29 into Equation 27, resulting:

$$
\frac{P_{m}}{M_{0}}=24.97\left(\frac{c}{h}\right)^{\frac{1}{a}}+4.30\left(2-\frac{\pi R^{2}}{c H i}\right)\left(\frac{c}{h}\right)^{\frac{1}{a}}+2.92\left(\frac{c}{h}\right)^{\frac{a}{a}}+2
$$

\subsubsection{Effective crushing distance $\left(\delta_{A}\right)$}

The equation of effective crushing distance for a square column with asymmetric mix collapse mode A can be written as follows:

$$
\frac{\delta_{A}}{2 H}=0.77
$$




\subsubsection{Mean static force $\left(\bar{P}_{m}\right)$}

By dividing Equation 30 by Equation 31, the following dimensionless equation can be used to predict the mean crushing load in a quasi-static test.

$$
\frac{p_{m}}{M_{0}}=32.43\left(\frac{c}{h}\right)^{\frac{1}{a}}+5.58\left(2-\frac{\pi R^{2}}{c H i}\right)\left(\frac{c}{h}\right)^{\frac{1}{a}}+3.79\left(\frac{c}{h}\right)^{\frac{a}{a}}+2.6
$$

\subsubsection{Material strain rate sensitivity $(\dot{\varepsilon})$}

The material strain rate in an axially crushed square tube for asymmetric mixed collapse mode A can be written as follows:

$$
\dot{\varepsilon}=0.49 \frac{V}{c}
$$

A detailed explanation can be found in Abramowicz and Jones (1984).

\subsubsection{Cowper Symonds}

The empirical formula of the Cowper-Symonds uniaxial constitutive equation is shown in Equation 21. By substituting Equation 33 into Equation 21, this gives:

$$
\frac{\sigma_{0}^{d}}{\sigma_{0}}=1+\left(0.49 \frac{V}{c D}\right)^{\frac{1}{p}}
$$

where $v=$ velocity, customary coefficient $D=40.4 s^{-1}$ and $p=5$ for mild steel.

3.2.6. Mean dynamic force $\left(\bar{P}_{m}{ }^{d}\right)$

Multiplying Equations 32 and 34 gives the mean dynamic crushing loads.

$$
\frac{p_{m}^{d}}{M_{0}}=\left\{1+\left(0.49 \frac{V}{c D}\right)^{\frac{1}{p}}\right\}\left\{32.43\left(\frac{\varepsilon}{h}\right)^{\frac{1}{a}}+5.58\left(2-\frac{\pi R^{2}}{c H i}\right)\left(\frac{c}{h}\right)^{\frac{1}{a}}+3.79\left(\frac{c}{h}\right)^{\frac{2}{a}}+2.6\right\}
$$

\subsubsection{Peak dynamic force $\left(\bar{P}_{\text {peak }}{ }^{d}\right)$}

Multiplying Equation 35, the experimental peak crushing force coefficient $\left(k_{0}\right)$, and the stress concentration coefficient $\left(k_{T}\right)$ gives the peak dynamic force (Nguyen et al., 2013).

$$
\frac{p_{\text {peak }}{ }^{d}}{M_{0}}=k_{0}\left(\frac{K_{T}}{3}\right)\left\{1+\left(0.49 \frac{V}{c D}\right)^{\frac{1}{p}}\right\}\left\{32.43\left(\frac{c}{h}\right)^{\frac{1}{a}}+5.58\left(2-\frac{\pi R^{2}}{c H i}\right)\left(\frac{c}{h}\right)^{\frac{1}{a}}+3.79\left(\frac{c}{h}\right)^{\frac{2}{a}}+2.6\right\}
$$

\subsubsection{Energy absorption $\left(E_{t}\right)$}

Multiplying the mean dynamic force and displacement of folding gives the energy absorption.

$$
E_{t}=\delta_{A} M_{0}\left\{1+\left(0.49 \frac{V}{c D}\right)^{\frac{1}{p}}\right\}\left\{32.43\left(\frac{c}{h}\right)^{\frac{1}{3}}+5.58\left(2-\frac{\pi R^{2}}{c H i}\right)\left(\frac{c}{h}\right)^{\frac{1}{3}}+3.79\left(\frac{c}{h}\right)^{\frac{2}{3}}+2.6\right\}
$$

\subsection{Asymmetric Mixed Collapse Mode B with Eight Holes}

\subsubsection{Mean force $\left(P_{m}\right)$}

According to Abramowicz and Jones (1984), asymmetric mixed collapse mode B consists of two layers, which have seven type-I and one type-II basic folding elements as internal energy, total initial height $4 \mathrm{H}$, and mean force as external energy. The formula can be written as follows:

$$
P_{m} 4 H=M_{0}\left(112 H I_{1} \frac{b}{h}+14 \pi c+28 I_{3} \frac{H^{2}}{b}+\frac{8 H^{2}}{h}+2 \pi c+4 H\right)
$$

Substituting the eight hole crush initiator element in Equation 12 into one layer horizontal hinge line in Equation 38 gives: 
with

$$
\frac{P_{m}}{M_{0}}=\left\{28 I_{1} \frac{b}{h}+\frac{\pi c}{H}\left(2-\frac{\pi R^{2}}{c H i}\right)+\frac{2 \pi c}{H}+7 I_{3} \frac{H}{b}+\frac{2 H}{h}+1\right\}
$$

and

$$
\frac{H}{h}=0.83\left(\frac{c}{h}\right)^{\frac{2}{3}}
$$

$$
\frac{b}{h}=0.65\left(\frac{c}{h}\right)^{\frac{1}{a}}
$$

By subtituting Equations 40 and 41 into Equation 39, yield:

$$
\frac{P_{m}}{M_{0}}=27.93\left(\frac{c}{h}\right)^{\frac{1}{a}}+3.78\left(2-\frac{\pi R^{2}}{c H i}\right)\left(\frac{c}{h}\right)^{\frac{1}{a}}+1.65\left(\frac{c}{h}\right)^{\frac{a}{a}}+1
$$

\subsubsection{Effective crushing distance $\left(\delta_{B}\right)$}

The effective crushing distance of asymmetric mixed collapse mode B on a square column can be written as:

$$
\frac{\delta_{B}}{2 H}=0.77
$$

\subsubsection{Mean crushing Force $\left(\bar{P}_{m}\right)$}

By dividing Equation 42 by Equation 43, the following dimensionless equation can be used to predict mean crushing load:

$$
\frac{p_{m}}{M_{0}}=36.27\left(\frac{c}{h}\right)^{\frac{1}{a}}+4.90\left(2-\frac{\pi R^{2}}{c H i}\right)\left(\frac{c}{h}\right)^{\frac{1}{a}}+2.14\left(\frac{c}{h}\right)^{\frac{a}{a}}+1.30
$$

\subsubsection{Material Strain Rate Sensitivity $(\dot{\varepsilon})$}

The effect of the material strain rate is shown in Equation 45:

$$
\dot{\varepsilon}=0.41 \frac{\mathrm{V}}{\mathrm{c}}
$$

A detailed explanation can be found in Abramowicz and Jones (1984).

\subsubsection{Cowper Symonds}

The empirical formula of the Cowper-Symonds uniaxial constitutive equation to show the relationship between static and dynamic load is shown in Equation 21. By substituting Equation 45 into Equation 21, the Cowper Symonds formula can then be written as:

$$
\frac{\sigma_{0}^{d}}{\sigma_{0}}=1+\left(0.41 \frac{V}{c D}\right)^{\frac{1}{p}}
$$

3.3.6. Mean Dynamic Force $\left(\bar{P}_{m}{ }^{d}\right)$

Multiplying Equations 44 and 46 gives the mean dynamic crushing loads.

$$
\frac{p_{m}^{d}}{M_{0}}=\left\{1+\left(0.41 \frac{V}{c D}\right)^{\frac{1}{p}}\right\}\left\{36.27\left(\frac{c}{h}\right)^{\frac{1}{a}}+4.90\left(2-\frac{\pi R^{2}}{c H i}\right)\left(\frac{c}{h}\right)^{\frac{1}{a}}+2.14\left(\frac{c}{h}\right)^{\frac{a}{a}}+1.30\right\}
$$

\subsubsection{Peak Dynamic Force $\left(\bar{P}_{\text {peak }}{ }^{d}\right)$}

Multiplying Equation 45 by the experimental peak crushing force coefficient $\left(\mathrm{K}_{0}\right)$, and the stress concentration coefficient $\left(\mathrm{K}_{\mathrm{T}}\right)$ predict the peak dynamic force (Nguyen et al., 2013).

$$
\frac{p_{p e a k}{ }^{d}}{M_{0}}=k_{0}\left(\frac{K_{T}}{3}\right)\left\{1+\left(0.41 \frac{V}{c D}\right)^{\frac{1}{p}}\right\}\left\{36.27\left(\frac{c}{h}\right)^{\frac{1}{a}}+4.90\left(2-\frac{\pi R^{2}}{c H i}\right)\left(\frac{c}{h}\right)^{\frac{1}{a}}+2.14\left(\frac{c}{h}\right)^{\frac{a}{a}}+1.30\right\}
$$




\subsubsection{Energy Absorption $\left(E_{t}\right)$}

Prediction of energy absorption can be calculated by multiplying the mean dynamic force and displacement of folding, giving:

$$
E_{t}=\delta_{B} M_{0}\left\{1+\left(0.41 \frac{V}{c D}\right)^{\frac{1}{p}}\right\}\left\{36.27\left(\frac{c}{h}\right)^{\frac{1}{3}}+4.90\left(2-\frac{\pi R^{2}}{c H i}\right)\left(\frac{c}{h}\right)^{\frac{1}{3}}+2.14\left(\frac{c}{h}\right)^{\frac{2}{3}}+1.30\right\}
$$

\subsection{Comparison to Abramowicz's Formula}

Abramowicz and Jones (1984) presented their prediction of the energy absorption occurring on a thin-walled square tube structure without crush initiator. All the modes of square tube collapse due to axial crushing could be predicted by using their formula. They proposed an equation to predict energy absorption in the symmetric collapse mode as:

$$
\frac{p_{m}^{d}}{M_{0}}=52.22\left\{1+\left(0.33 \frac{V}{c D}\right)^{\frac{1}{p}}\right\}\left(\frac{c}{h}\right)^{\frac{1}{a}}
$$

The equation for asymmetric mixed collapse mode $\mathrm{A}$ is:

$$
\frac{p_{m}^{d}}{M_{0}}=\left\{1+\left(0.49 \frac{V}{c D}\right)^{\frac{1}{p}}\right\}\left\{43.61\left(\frac{c}{h}\right)^{\frac{1}{a}}+3.79\left(\frac{c}{h}\right)^{\frac{2}{a}}+2.6\right\}
$$

and the equation for asymmetric mixed collapse mode B is:

$$
\frac{p_{m}^{d}}{M_{0}}=\left\{1+\left(0.41 \frac{V}{c D}\right)^{\frac{1}{p}}\right\}\left\{46.16\left(\frac{c}{h}\right)^{\frac{1}{a}}+2.14\left(\frac{c}{h}\right)^{\frac{3}{a}}+1.3\right\}
$$

This study proposes the prediction of energy absorption occurring in a thin-walled square tube structure; however, this study considers a crush initiator. The proposed equation for symmetric collapse mode is shown as Equation 23, while that for the prediction of asymmetric mixed collapse mode A is Equation 35 and for asymmetric mixed collapse mode B Equation 47. The proposed formulas display a similar trend with Abramowicz's Formulas.

\subsection{Validation of the Prediction with the Experimental Data}

The results of the mathematical calculation or theoretical analysis need to be validated with the experimental data of the drop test to ensure that the mathematical formula is close to the actual results. The theoretical analysis was compared with the experimental results of specimen A (c/h $=60.42)$ and B $(\mathrm{c} / \mathrm{h}=45.49)$, as shown in Figure 4 (Sumarsono et al., 2015; Malawat et al., 2017; Malawat \& Sumarsono, 2017). The differences between the theoretical analyses and the experimental results for peak crushing force were around $10 \%$ and $4 \%$ for specimens $\mathrm{A}$ and $\mathrm{B}$, and for mean crushing force they were around $10 \%$ and $7 \%$ for specimens $\mathrm{A}$ and $\mathrm{B}$, respectively. At the $90 \%$ confidence level, the degree of the differences is still acceptable.

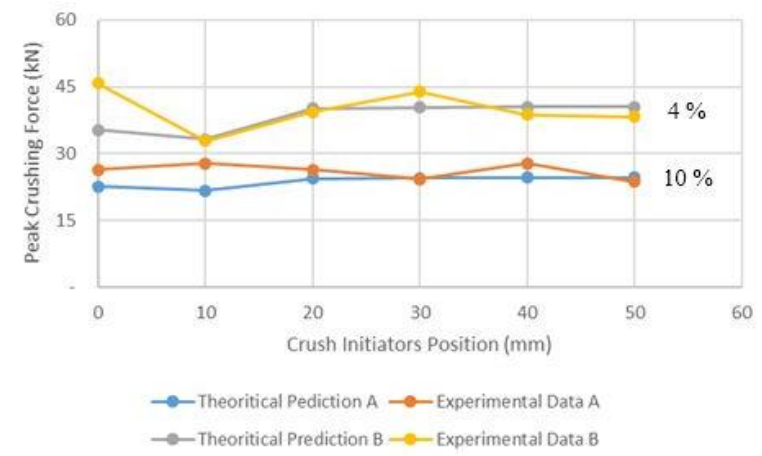

(a)

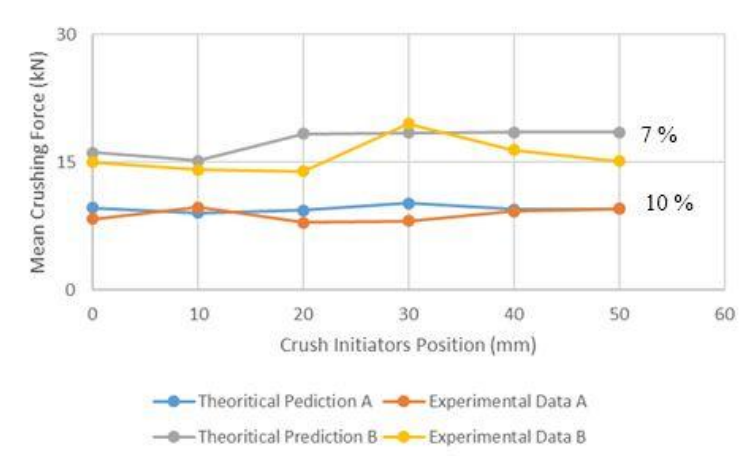

(b)

Figure 4 Validation of theoretical prediction with experimental drop test data 
The most important factor in the calculation is yield strength; that of specimens A and B is 225 MPa and $265 \mathrm{MPa}$ respectively (Sumarsono et al., 2015; Malawat et al., 2017; Malawat \& Sumarsono, 2017).

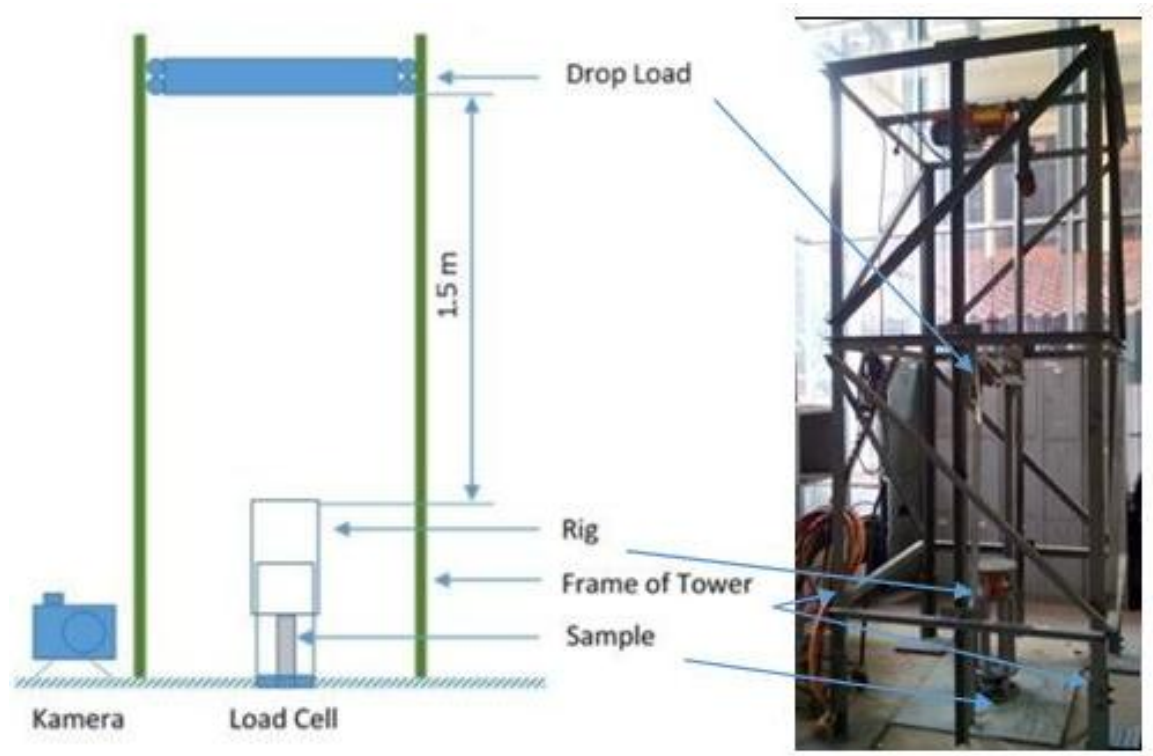

(a)

(b)

Figure 5 Drop test tower

An experimental study was conducted at the Laboratory of Technology Mechanics, Department of Mechanical Engineering, University of Indonesia. A $3 \mathrm{~m}$ drop tower was used to generate the impact energy with an effective dropping load of $1.5 \mathrm{~m}$. A $80 \mathrm{~kg}$ drop load mass was placed in the center of the dropping line. A sketch and photograph of the drop tower are shown in Figures 5a and 5b, respectively (Malawat et al., 2017).

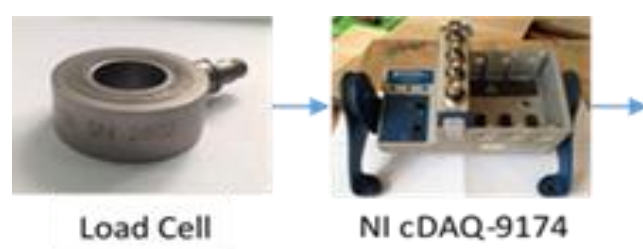

Load Cell

$$
\text { NI cDAQ-9174 }
$$

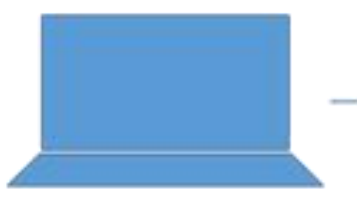

LabVIEW 2011

NI 9234

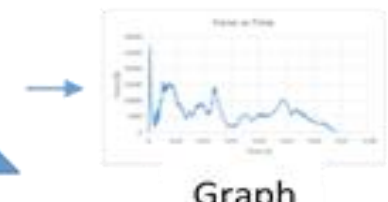

Force vs Time

Figure 6 Acquisition process of data in drop test

The study used load cell PCB Piezotronics with serial number 203B ICP and $88.96 \mathrm{kN}$ capacity. The signal from the load cell was connected to the computer using NI cDAQ-9174 and NI 9234, with a sampling rate of 51.2-kilo sample per second. LabVIEW Professional Development System 2011 software was used to display the results in a graph. The flow of the data acquisition process is shown in Figure 6 (Malawat et al. 2017). Similar data acquisition arrangements were used by Dionisius et al. (2017) to validate their numerical simulations in an impact transferability model. 


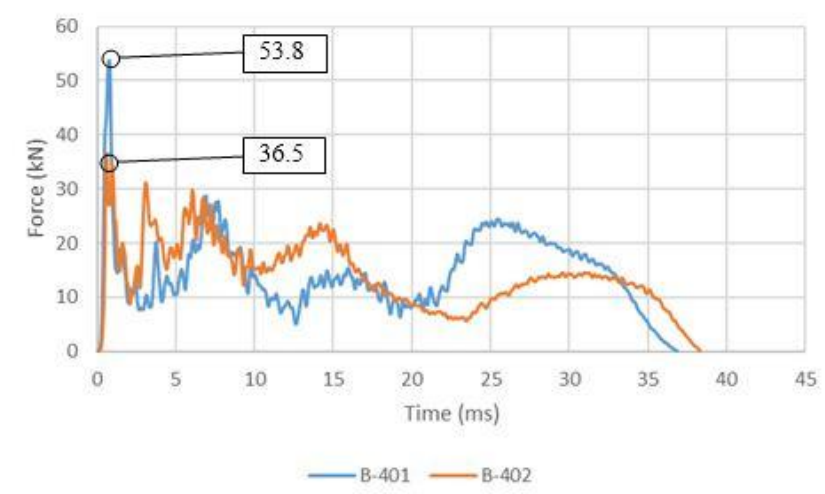

Figure 7 Results of drop test

Figure 7 shows the experimental results of the drop test. They indicate the relationship between force $(\mathrm{kN})$ and time $(\mathrm{ms})$. The blue line represents the results of specimen B-401 (without crush initiator), while the red line shows the result of specimen B-402 (with crush initiator, $10 \mathrm{~mm}$ from the edge). The results indicate that the peak crushing force was $53.8 \mathrm{kN}$ and $36.5 \mathrm{kN}$ for B-401 and B-402 respectively. This means that the crush initiator influenced the reduction in peak crushing force (Sumarsono et al., 2015).

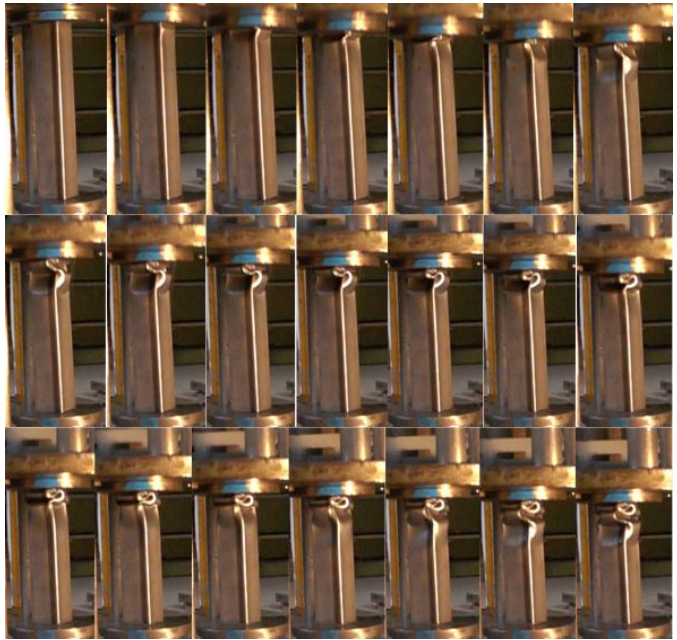

(a)

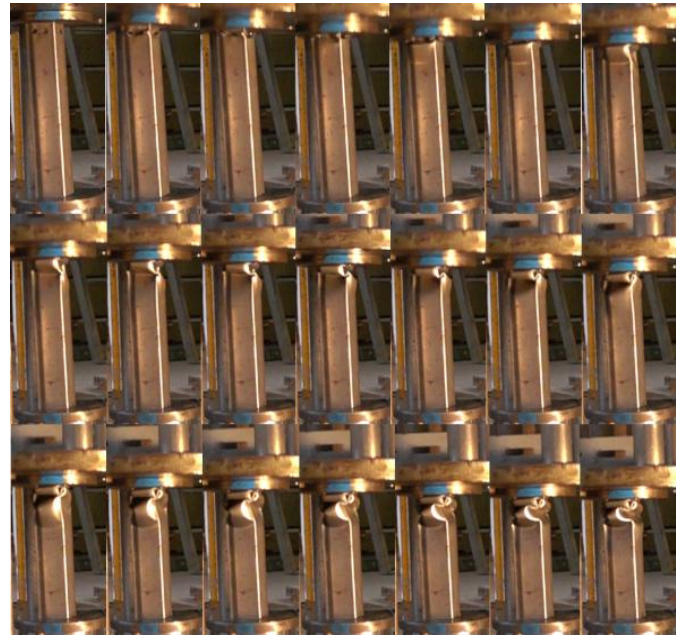

(b)

Figure 8 Process of axial crushing on specimen square tube: (a) without crush initiator; and (b) with crush initiator

Figure 8 shows the process of proportional folding on the specimen square tube. The pictures were taken by a high speed camera (960 fps). For the square tube without crush initiator (a), the first folding started at a certain distance from the upper end, while for the square tube with crush initiator, whose position is $10 \mathrm{~mm}$ from the upper end, the first folding started on the crush initiator. This proves that a crush initiator is needed as an initial folding guide.

\section{CONCLUSION}

This work has presented a comparison between theoretical and experimental analysis of the behavior of a thin-walled square tube structure under axial crushing. For the symmetric collapse mode, the formula for predicting mean dynamic force is shown as Equation 23; for peak crushing force as Equation 24; and for energy absorption as Equation 25. For asymmetric mixed collapse mode A, the formula for predicting mean dynamic force is shown as Equation 35; for peak crushing force as Equation 36; and for energy absorption as Equation 37. For 
asymmetric mixed collapse mode $\mathrm{B}$, the formula for predicting mean dynamic force is shown as Equation 47; for peak crushing force as Equation 48; and for energy absorption as Equation 49. The theoretical analysis shows close agreement with the experimental drop test study.

\section{ACKNOWLEDGEMENT}

The authors greatly appreciate the Departemen Riset dan Pengabdian Masyarakat Universitas Indonesia for the research grant Year 2015 by Hibah Riset Pascasarjana 2015.

\section{REFERENCES}

Abramowicz, W., Jones, N., 1984. Dynamic Axial Crushing of Square Tubes. International Journal of Impact Engineering, Volume 2(2), pp. 179-208

Deng, X., Liu, W., Lin, Z., 2018. Experimental and Theoretical Study on Crashworthiness of Star-shaped Tubes under Axial Compression. Thin-Walled Structures, Volume 130, pp. 321-331

Ding, X., Zeqi, T., Liu, Y., Liu, S., 2018. Dynamic Axial Crush Analysis and Design Optimization of a Square Multi-cell Thin-walled Tube with Lateral Variable Thickness. International Journal of Mechanical Sciences, Volume 140, pp. 13-26

Dionisius, F., Istiyanto, J., Suliono., Rohmat, Y.R., 2017. Pengembangan Pengujian Crashworthiness dengan Simulasi Numerik Menggunakan Impact Transferability (Development of Crashworthiness Testing with Numerical Simulation using Impact Transferability). Jurnal Teknologi Terapan, Volume 3(1), pp. 12-17

Ge, C-Q., Gao, Q., Wang, L., 2018. Theoretical and Numerical Analysis of Crashworthiness of Elliptical Thin-walled Tube. International Journal of Mechanical Sciences, Volume 148, pp. 467-474

Googarchin, H.S., Pasandidehpoor, M., Mahmoodi, A., Shojaeefard, M.H., 2019. Energy Absorption Analysis for Tapered Multi-cell Tubes Improved by Foams: Theoretical Development and Numerical Simulation. Composite Structures, Volume 207, pp. 213-222

Hu, D., Wanga, Y., Songa, B., Danga, L., Zhang, Z., 2019. Energy-absorption Characteristics of a Bionic Honeycomb Tubular Nested Structure Inspired by Bamboo under Axial Crushing. Composites Part B: Engineering, Volume 162, pp. 21-32

Mahbod, M., Asgari, M., 2018. Energy Absorption Analysis of a Novel Foam-filled Corrugated Composite Tube under Axial and Oblique Loadings. Thin-Walled Structures, Volume 129, pp. $58-73$

Malawat, M., Istiyanto, J., Sumarsono, D.A., 2017. Effects of Wall Thickness and Crush Initiators Position under Experimental Drop Test on Square Tube. Applied Mechanics and Material, Volume 865, pp. 612-618

Malawat, M., Sumarsono, D.A., 2017. Optimization of Impact Energy Absorber Parameters for Automobile Crush Box using Response Surface Method. In: Proceedings of Quality in Research 2017, Bali, July 24-27 , Volume 15, pp. 333-339

Najafi, A., Rais-Rohani, M., 2011. Mechanics of Axial Plastic Collapse in Multi-cell, MultiCorner Crush Tubes. Thin-Walled Structures, Volume 49(1), pp. 1-12

Nguyen, C.N., Dirgantara, T., Gunawan, L., Putra, I.S., Ly, H.A., 2013. Analytical Prediction of Square Crash Box Structure with Holes Due to Impact Loading. In: Regional Conference on Mechanical and Aerospace Technology 2013, Kuala Lumpur, November $25-26^{\text {th }}$

Palomba, G., Epasto, G., Crupi, V., Guglielmino, E., 2018. Single and Double-layer Honeycomb Sandwich Panels under Impact Loading. International Journal of Impact Engineering, Volume 121, pp. 77-90 
Shena, W., Gu, X., Jiang, P., Hu, J., Lv, X., Qian, L., 2017. Crushing Analysis and Multi Objective Optimization Design for Rectangular Unequal Triple-cell Tubes Subjected to Axial Loading. Thin-Walled Structures, Volume 117, pp. 190-198

Sumarsono, D.A., Istiyanto, J., Malawat, M., 2015. Pengembangan Impact Energy Absorber Dengan Pengaturan Jarak Crash Initiators (Development of Impact Energy Absorber with Distance Management of Crash Initiators). In: Prosiding Seminar Nasional Tahunan Teknik Mesin XIV 2015, Banjarmasin, Volume 15

Sun, G., Pang, T., Xu, C., Zheng, G., Song, J., 2017. Energy Absorption Mechanics for Variable Thickness Thin-walled Structures. Thin-Walled Structures, Volume 118, pp. 214 228

Tran, T.N., 2017. Crushing and Theoretical Analysis of Multi-cell Thin-walled Triangle Tube under Lateral Loading. Thin-Walled Structures, Volume 115, pp. 205-214

Xie, S., Yang, W., Wang, N., Li, H., 2017. Crashworthiness Analysis of Multi-cell Square Tubes under Axial Loads. International Journal of Mechanical Sciences, Volume 121, pp. 106-118

Xiong, F., Wang, D., Yin, S., 2018. Optimization Analysis of Novel Foam-filled Elliptical Columns under Multiple Oblique Impact Loading. Materials and Design, Volume 156, pp. 198-214

Zhang, J., Lu, B., Zheng, D., Li, Z., 2019. Axial Crushing Theory of Metal-FRP Hybrid Square Tubes Wrapped with Antisymmetric Angle-ply. Thin-Walled Structures, Volume 137, pp. 367-376

Zhang, Y., Xu, X., Wang, J., Tengteng, C., Wang, C.H., 2018. Crushing Analysis for Novel Bio-inspired Hierarchical Circular Structures Subjected to Axial Load. International Journal of Mechanical Sciences, Volume 140, pp. 407-431 